\title{
Acquired Palatal Fistula in Patients with Submucous and Incomplete Cleft Palate before Surgery
}

\author{
Ie Hyon Park ${ }^{1}$, Jee Hyeok Chung ${ }^{1}$, Tae Hyun Choi ${ }^{1}$, Jihyeon Han², Suk Wha Kim ${ }^{1}$ \\ ${ }^{1}$ Division of Pediatric Plastic Surgery, Seoul National University Children's Hospital, Seoul; ${ }^{2}$ Department of Plastic and Reconstructive \\ Surgery, Seoul National University Bundang Hospital, Seoul National University College of Medicine, Seongnam, Korea
}

It is uncommon for a palatal fistula to be detected in individuals who have not undergone surgery, and only sporadic cases have been reported. It is even more difficult to find cases of acquired palatal fistula in patients with submucous or incomplete cleft palate. Herein, we present 2 rare cases of this phenomenon. Case 1 was a patient with submucous cleft palate who acquired a palatal fistula after suffering from oral candidiasis at the age of 5 months. Case 2 was a patient with incomplete cleft palate who spontaneously, without trauma or infection, presented with a palatal fistula at the age of 9 months.

Keywords Fistula / Oral fistula / Cleft palate
Correspondence: Suk Wha Kim Division of Pediatric Plastic Surgery, Seoul National University Children's Hospital, 101 Daehak-ro Jongno-gu, Seoul 03080, Korea

Tel: $+82-2-2072-3530$

Fax: +82-2-2072-3680

E-mail:kimsw@snu.ac.kr

This case was presented as a poster at the 73rd Congress of the Korean Society of Plastic and Reconstructive Surgeons on Nov 11-13, 2015 in Seoul, Korea.

No potential conflict of interest relevant to this article was reported.

\section{INTRODUCTION}

Palatal fistula is a relatively common postoperative complication. However, it is unusual for a palatal fistula to be found in patients who have not undergone surgery. Only sporadic cases of congenital palatal fistula have been reported [1-8]. Even fewer cases have been reported of acquired palatal fistula in cleft palate patients [911]. This report presents 2 clinical cases of acquired palatal fistula without any apparent associations with surgery or trauma.

\section{CASES}

\section{Case 1}

A 2-month-old girl presented with a bifid uvula without any other abnormal findings. At that time, no zona pellucida was apparent. She had no family history of congenital anomalies. The pregnancy had been uncomplicated and the patient did not have a history of trauma. She had no underlying diseases other than a sacrococcygeal dimple, which was under observation. Since birth, she had experienced difficulty sucking; hence, powdered milk feeding with a specialized bottle was initiated instead of breastfeeding. A total of 11 weeks after the first visit, she was referred for loss of appetite and was diagnosed with oral candidiasis. At the time of referral, the patient had a whitish palatal ulcer (Fig. 1). She was prescribed an oral antifungal agent and the disease continued its course for 3 days. However, after a week, she refused oral feeding and a leaking sound was observed when she sucked on a bottle. After 5 days of antifungal therapy, no 
more clinical evidence of disease progression was found. Upon examination, a small palatal fistula was detected at the junction of the hard and soft palate, and according to her parents, the fistula had increased in size over time (Figs. 2-4).

\section{Case 2}

A 3-month-old boy presented with a cleft palate. He was born after an uncomplicated full-term pregnancy, without any other underlying disease. He was initially diagnosed with an incomplete cleft palate involving only the soft palate, and exhibited a palpable notch and a zona pellucida confined to the posterior

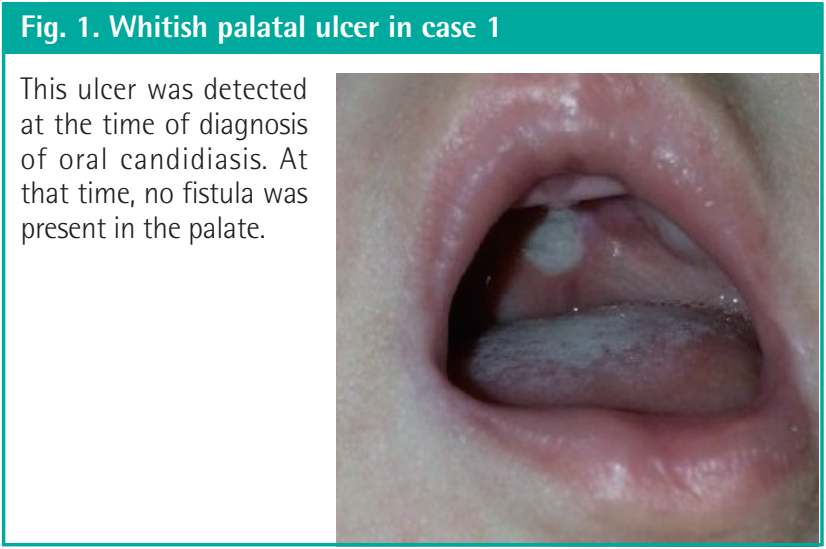

\section{Fig. 2. Palatal fistula in case 1}

This fistula was observed after the resolution of the fungal infection. A small hole was detected at the junction of the hard and soft palate.

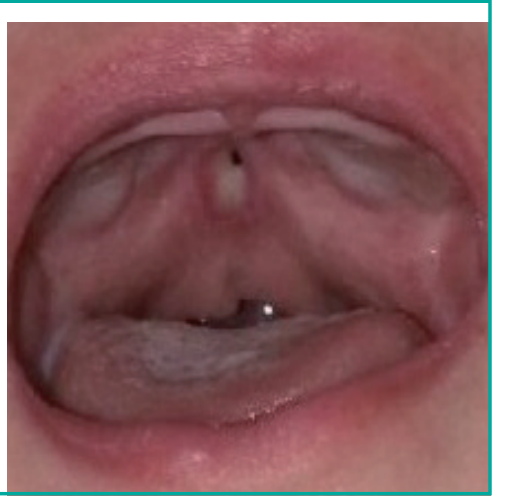

\section{Fig. 3. Preoperative design in case 1}

The posteriorly based flap on the left-side of the palate and the anteriorly based flap on the right-side of the palate had angles of $60^{\circ}$.

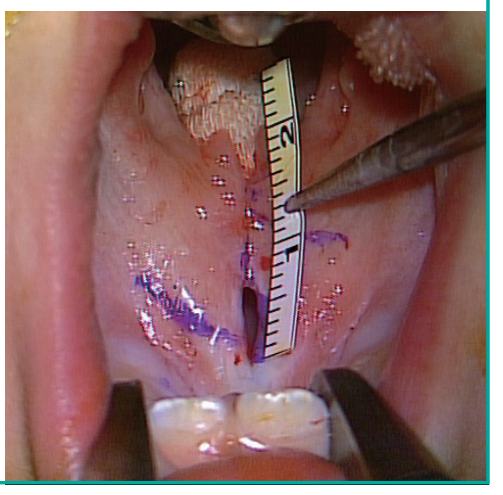

hard palate at the age of 3 months. After 6 months, a fistula was observed in the posterior third of the hard palate. According to his parents, no remarkable events had occurred between the visits. The fistula was $1 \times 3 \mathrm{~mm}$ in size and located at the junction of the soft and hard palate (Figs. 5, 6).

\section{Surgery}

In both patients, the fistula and cleft palate were simultaneously repaired using Furlow double-opposing Z-plasty at the age of 14 months. The incision line was drawn along the margin of the fistula and was subsequently extended along the midline of the

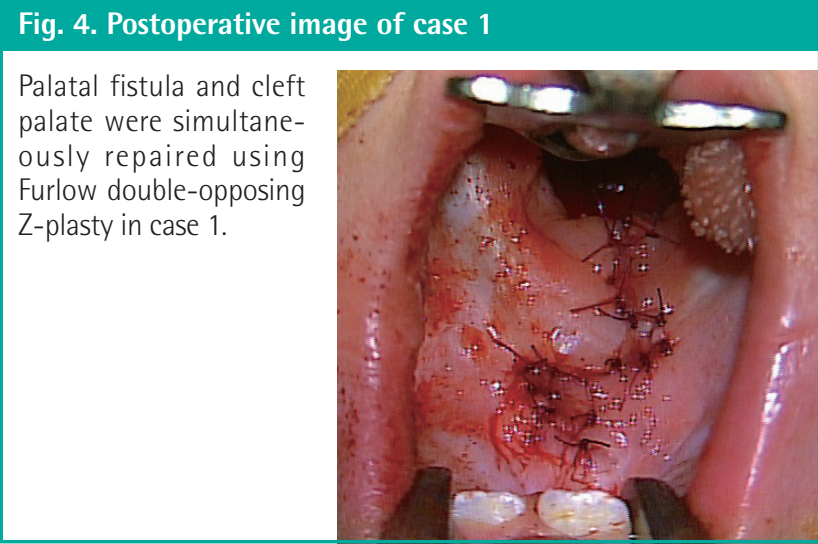

Fig. 5. Preoperative image of case 2

A $1 \times 3-m m$ fenestration was observed at the junction of the hard and soft palate.

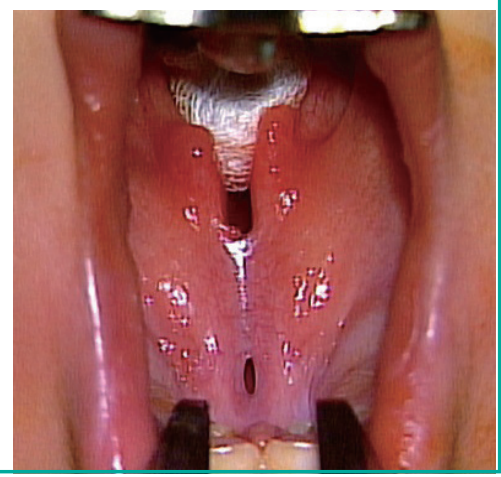

\section{Fig. 6. Postoperative image of case 2}

Palatal fistula and cleft palate were simultaneously repaired using Furlow double-opposing Z-plasty in case 2.

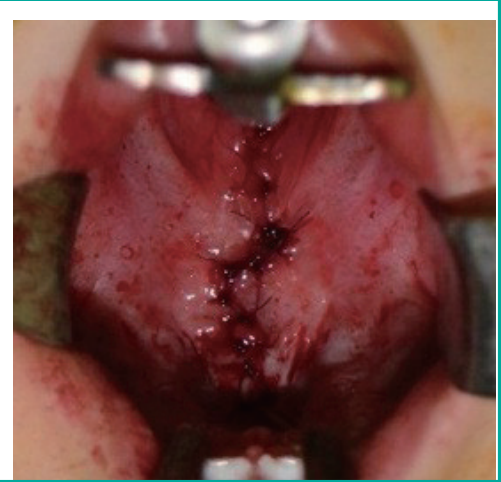


soft palate and uvula. Dissection was performed without difficulty and a bony defect of the hard palate was detected during the surgery. The patients were discharged without any complications, including recurrent fistula (Figs. 4, 6).

\section{DISCUSSION}

Although palatal fistula is one of the most common complications of cleft palate surgery, its presentation in patients who have not undergone surgery is rare, and the cases that have been reported involved submucous cleft palate [1-7]. In 1931, Veau and Borel [8] first reported the phenomenon of congenital palatal fistula. Since then, approximately 30 cases have been reported in the literature worldwide. The majority of the reported cases presented with palatal fistula at birth or it was not stated whether the fistulae were acquired after birth or otherwise. Fara [2] reported that congenital defects of the hard palate were involved in $0.17 \%$ of cleft palates, $0.32 \%$ of isolated medial palate clefts, and $6.02 \%$ of submucous cleft palates. Mehendale and Sommerlad [5] reported that $2.17 \%$ of submucous cleft palate patients presented with perforation.

However, in the present case, the palatal fistulae were acquired after birth, indicating that they were not congenital. Very few reports of acquired palatal fistulae have been published. Similar to this case, Karabulut et al. [9] reported hard palate perforation due to invasive aspergillosis in patients with acute lymphoblastic leukemia. However, those patients suffered from an immunosuppressive disease and thus were vulnerable to fungal infections. Two reports similar to the present case have been published, describing cases of acquired palatal fistula with an isolated cleft palate. Weijerman and Heybroek [10] reported perforation in a case of submucous cleft palate due to an aphthous ulcer. Guzel et al. [11] reported a case of palatal fistula that developed after primary tuberculous dacryoadenitis. However, in these cases, the perforation occurred when the patients were adults, at the ages of 20 and 40 years, respectively.

The mechanism of palatal fistula in patients who have not undergone surgery is debatable. The controversy lies in whether the prenatal or postnatal palatal fistula is acquired secondary to destruction of the thin mucosa in a submucous cleft palate or is an isolated condition regardless of cleft palate. Fara [2] proposed that it is due to the intrauterine rupture of a wide submucous cleft in the area of the greatest tension, which is the posterior part of the hard palate. Furthermore, in other studies, the mucosa in the submucous cleft palate was intact at birth but subsequently presented with a hole, suggesting spontaneous rupture or a traumatic etiology $[5,6,10]$. In several reports, submucous cleft palate was not accompanied by palatal perforation, suggesting that it occurred due to an embryological malformation $[1,3]$. The present case strongly supports the former etiology; that is, oral candidiasis was the cause of palatal fenestration, which is supported by the photograph taken before the perforation (Fig. 1).

In the present case report, case 1 is notable in that it is the first case of acquired palatal fistula to have occurred in a patient with suspected submucous cleft palate in early infancy due to oral candidiasis. Although oral candidiasis is prevalent in patients with acquired immune deficiency syndrome, in immunocompromised patients, or in patients taking glucocorticosteroids, superficial infections are not uncommon in infants and the elderly [12]. Furthermore, the photograph taken before the perforation demonstrates the patient's clinical history, whereas previous reports only contain narrations of patients' histories. Case 2 is remarkable in that the palatal mucosa was perforated spontaneously in an area that was discontinuous with the existing incomplete cleft.

Unlike the other forms of cleft palate, submucous cleft palate may not result in speech disorders [13]. Submucous cleft palate is associated with poorer speech outcomes after surgery than incomplete cleft palate [14]. Therefore, it is widely accepted that surgical correction should be delayed until the age of 3 or 4 years, when velopharyngeal incompetence becomes apparent. Here, we that recommend surgeons observe submucous and incomplete cleft patients regularly before surgery, as palatal perforation may occur spontaneously.

\section{REFERENCES}

1. Lynch JB, Lewis SR, Blocker TG Jr. Cleft palate not explained by embryology. Plast Reconstr Surg 1966;38:552-4.

2. Fara M. Congenital defects in the hard palate: observation of five cases. Plast Reconstr Surg 1971;48:44-7.

3. Rogers GF, Murthy A, Mulliken JB. Congenital fenestration of the palate: a case of embryologic syzygy. Cleft Palate Craniofac J 2006;43:363-6.

4. Cheng N, Zhou M. Congenital fistula of the palate. J Craniomaxillofac Surg 1998;26:391-3.

5. Mehendale FV, Sommerlad BC. Submucous cleft palates presenting with a perforation. Cleft Palate Craniofac J 2003; 40:203-6.

6. Eshete M, Camison L, Abate F, et al. Congenital palatal fistula associated with submucous cleft palate. Plast Reconstr Surg Glob Open 2016;4:e613.

7. Abdel-Aziz M. Congenital palatal fistula in a patient with submucous cleft palate. J Plast Reconstr Aesthet Surg 2009; 62:e509-10.

8. Veau V, Borel S. Division palatine: anatomie, chirurgie, pho- 
netique. Paris: Masson; 1931.

9. Karabulut AB, Kabakas F, Berkoz O, et al. Hard palate perforation due to invasive aspergillosis in a patient with acute lymphoblastic leukemia. Int J Pediatr Otorhinolaryngol 2005;69:1395-8.

10. Weijerman JE, Heybroek G. Perforation in a case of submucous cleft palate due to an aphthous ulcer. Br J Oral Surg 1972;10:217-9.

11. Guzel MZ, Kilic A, Arslan H. Palatal fistula: a complication of primary tuberculous dacryoadenitis. J Plast Reconstr Aesthet Surg 2008;61:1105-7.
12. Pappas PG, Bergamo B. Superficial and mucosal fungal infections. In: Maertens JA, Marr KA, editors. Diagnosis of fungal infections. New York: Informa Healthcare; 2007. p.153-69.

13. McWilliams BJ. Submucous clefts of the palate: how likely are they to be symptomatic? Cleft Palate Craniofac J 1991; 28:247-9.

14. Park TS, Bae YC, Nam SB, et al. Postoperative speech outcomes and complications in submucous cleft palate patients. Arch Plast Surg 2016;43:254-7. 